\title{
Suspected cases of COVID-19 pneumonia in patients with slow-resolving respiratory tract infections: the reverse path of primary care during first wave of Pandemia in Lombardy, Italy
}

\author{
SESSA A ${ }^{1,2}$, SCIENZA $\mathbf{G}^{1,2}$, CLERICI $\mathbf{G}^{1}$, LUMIA $D^{3}$ \\ 'General Practitioner, ATS Insubria (Varese and Como), Italy. \\ ${ }^{2}$ Italian College of General Practitioners and Primary Care, Varese, Italy. \\ ${ }^{3}$ Radiologist, Nuovo Centro Fisioterapico, Varese (Italy).
}

*Address for Correspondence: Aurelio Sessa, General Practitioner, Italian College of General Practitioner and Primary Care, Varese, Italy; E mail: sessa.aurelio@simg.it

Received: 26 September 2020; Accepted: 30 November 2020; Published: 02 December 2020

Citation of this article: SESSA A, SCIENZA G, CLERICI G, LUMIA D (2020) Suspected cases of COVID-19 pneumonia in patients with slow-resolving respiratory tract infections: the reverse path of primary care during first wave of Pandemia in Lombardy, Italy. Rea Int J of Community med and Pub Health. Rea Int J of Community med and Pub Health. 1(1): 042-046.

DOI: $10.37179 /$ rijemph.000008.

Copyright: (C) 2020 SESSA A, et al. This is an open access article distributed under the Creative Commons Attribution License, which permits unrestricted use, distribution, and reproduction in any medium, provided the original work is properly cited.

\begin{abstract}
At the end of 2019, a series of pneumonia cases of unknown origin emerged in Wuhan (China). After few weeks, a novel virus coronavirus-2 was identified as causative agent for that pneumonia cluster. Coronavirus Disease 2019 (COVID-19) is responsible of pandemia that currently has involved all countries in the world. During the months of march and april 2020 some cases of patients with slow-resolving respiratory tract infection (RTI) attracted the attention of general practitioners (GPs) for suspicious of a COVID-19 infection. Because in that period the Reverse Trascriptase Polymerase Chain Reaction (RT-PCR) was performed only for hospitalized patients, it has been agreed for a path off diagnostic investigations (chest CT and laboratory test) to identify pneumonia attributable to COVID, respiratory complication at risk of hospitalization for acute respiratory distress. 66 out of 151 patients with slow-resolving RTI presented at chest CT pattern attributable to COVID-19 pneumonia. Moreover, high erythrocyte sedimentation rate (ESR), high C-reactive protein (CRP), high lactic dehydrogenase (LDH) and leukopenia are laboratory findings different between patients with chest CT abnormalities and patients with normal chest CT. All 66 patients were then positive at IgM-IgG combined antibody test for COVID-19, when it has been possible to make them. Early identification of COVID-19 pneumonia in patients with slow-resolving RTI, the prompt treatment, the remote consultation and assessment can prevent severe complication as severe acute respiratory syndrome (SARS) responsible of hospitalization and intensive care unit admission. 63 out of 66 patients with COVID-19 pneumonia has been cared at their home without hospitalization.
\end{abstract}

Keywords: COVID-19, COVID-19 pneumonia, chest computed tomography, primary care.

\section{Introduction}

At the end of 2019, a series of pneumonia cases of unknown origin emerged in Wuhan (China) [1]. A few weeks later, in January 2020, deep sequencing analysis from lower respiratory tract samples identified a novel virus severe acute respiratory syndrome coronavirus
2 (SARS-COV-2) as causative agent for that observed pneumonia cluster [2]. COVID-19 (Corona Virus Disease-2019) is an infectious disease caused by the Coronavirus SARS-COV-2 recently identified and responsible for the Pandemia that currently has involved 215 countries in the world [3] with over 32 million people affected and over 980 thousand deaths (September 25, 2020). 
Citation: SESSA A, SCIENZA G, CLERICI G, LUMIA D (2020) Suspected cases of COVID-19 pneumonia in patients with slowresolving respiratory tract infections: the reverse path of primary care during first wave of Pandemia in Lombardy, Italy. Rea Int $J$ of Community med and Pub Health.. Rea Int J of Community med and Pub Health. 1(1): 042-046.

DOI: $10.37179 /$ rijcmph.00008.

\section{Severity of COVID-19}

The clinical manifestations of COVID-19 are protean, including asymptomatic carrier, acute respiratory distress and pneumonia with varying degrees of severity [4]. The most frequent symptoms of COVID-19 infection are typical and common to infections caused by other respiratory viruses such as fever, dry cough, asthenia, sore throat, headache and dyspnea. Some patients report muscle aches, chills, nausea, diarrhea, loss of taste and/or smell [5]. These symptoms begin gradually and are mild in most cases. There are individuals who, although infected, do not develop any symptom (asymptomatic). Most people (about 80\%) recover from the disease without any specific treatment but only with symptomatic drugs.

In the first wave of the epidemic (march and april) in Italy 10$15 \%$ of infected people became seriously ill and developed important respiratory symptoms and $3 \%$ presented a critical situation evolving in admission to the Intensive Care Unit. Elderly people and/or patients with chronic diseases were more likely to develop a disease with a more severe course (85.3\% of deaths occurred in the over 70 s) [6]. In Italy, the number of deaths is $11.7 \%$ among COVID-19 patients (35,800 cases out of 306,000 notified in $202025^{\text {th }}$ September) and nearly 30,000 healthcare workers are infected. The incubation period is estimated to range from a few days up to 14 days with an average of 5.2 days $[7,8]$ during this time people may already be infected and therefore transmit the infection, without showing obvious symptoms of disease.

\section{Aim of the Study}

In the daily management of patients with respiratory tract infection (RTI) in the period of the COVID-19 epidemic in Italy, every general practitioner (GP) has managed many patients with symptoms attributable to respiratory virosis caused by influenza, by other respiratory viruses or by COVID-19. Lombardy has been the Region with the most of patients with COVID-19 infection in Italy (37\%). The influenza epidemic curve in March was in a sub-threshold situation (on average 1 case per 1000 population) therefore the risk of confusing a COVID-19 infection with influenza was negligible [9]. Lombardy Region had decided, in the initial phase of the epidemic, that real-time Reverse Transcriptase Polymerase Chain Reaction (rRT-PCR) tests for the identification of COVID were made only for those admitted for hospitalization, so an important symptomatic (but also asymptomatic) part of the population remained without an etiological diagnosis.

This population, calculated as at least 5 times as many official COVID-19 positive patients, presented a very wide range of symptoms attributable to the clinical pictures already described in the literature [10]. Some of patients, defined as "slow-resolving" RTI, attracted attention to GPs, as even 10 days after the onset of symptoms, they still presented fever (from 37.5 to $38.5^{\circ} \mathrm{C}$ ), non-productive cough, joint pain, asthenia, breathlessness and/or oxygen saturation $\leq 95 \%$ despite having followed symptomatic therapy (usually paracetamol 2000-3000 mg/day and/or other symptomatic drugs). The hypothesis that they had a COVID-19 infection was strong either because they reported close contact with positive index cases or because they came from areas with major epidemic outbreaks (Table 1).

\section{Methods}

It was agreed for these patients, to proceed with clinical investigations in order to understand the reason for a clinical picture with such slow resolution in the suspicion of a serious respiratory involvement secondary to possible COVID-19 infection. We identified and shared a diagnostic pathway that was based on a panel of imaging and laboratory investigations collected from current scientific literature [11, 12] (Table 2). Patients with clinical characteristics of slow-resolving RTI had the possibility of accessing for these diagnostic procedures within 24-48 hours after GP's prescription and

Table 1: Case definition of slow-resolving RTI.

Presence of main symptoms lasting at least 8 days, despite treatment with symptomatic drugs

Fever

Non-productive cough

Breathelessness

Asthenia

Presence of at least one of the secondary symptoms

Muscle and joint pain

Diarrhoea

Taste disturbances

Smell disturbances

Close contact with "index" case

Origin from areas with epidemic outbreaks

Table 2: Panel of diagnostic investigations for patients with slowresolving RTI.

White blood cell (WBC)

C-Reactive Protein (C-RP)

Erythrocyte sedimentation rate (ESR)

Aspartate transaminase (AST)

Alanine transaminase (ALT)

Lactate dehydrogenase (LDH)

Chest Computed Tomography (CT)

to have in the same day the results of the investigations allowing to proceed with the necessary therapeutic and public health measures.

\section{Statistical Analyses}

Statistical analyses were performed using the software Excel (Microsoft, Redmond, WA, USA). Comparisons of the laboratory tests between suspected COVID-19 pneumonia (positive) and patients without chest CT abnormalities were performed using difference between means of two sample t-test. Positive predictive value (PPV) was calculated as the ratio between the true-positive patients having C-RP, ESR, AST, ALT and LDH above the proposed cut-off, for WBC below the proposed cut-off. Differences between patients with chest CT pneumonia due to COVID-19 and negative group were considered statistically significant if $\mathrm{p}$-value was lower than 0.05 .

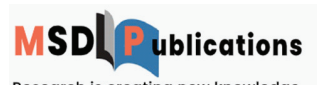

Research is creating new knowledge 
Citation: SESSA A, SCIENZA G, CLERICI G, LUMIA D (2020) Suspected cases of COVID-19 pneumonia in patients with slowresolving respiratory tract infections: the reverse path of primary care during first wave of Pandemia in Lombardy, Italy. Rea Int $\mathrm{J}$ of Community med and Pub Health.. Rea Int J of Community med and Pub Health. 1 (1): 042-046.

DOI: $10.37179 /$ rijcmph.00008.

\section{Results}

151 patients who had symptoms compatible with a slow-resolving RTI had access to the shared diagnostic path. The demographic characteristics of these patients are shown in (Table $3 \mathrm{~g}$ ). We found that the mean age of the patients with abnormal chest CT was older than patients with normal chest CT. The radiological picture on the chest CT was found to be normal in 69 subjects (45.7\%) while the remaining 82 had abnormalities (Figure 1). For 12 patients, the picture was defined as doubtful by radiologists with minimal

Table 3: Characteristics of patients of the study.

$* \mathrm{t}=1,86 \mathrm{p}$ value $=0.023$

All Patients with slow-resolving RTI

\begin{tabular}{|c|c|c|c|}
\hline & $\mathrm{N}$ & $\begin{array}{c}\text { Mean age } \\
\text { (years) }\end{array}$ & $\mathrm{SD}$ \\
\hline Males & 70 & 46.4 & 15.51 \\
\hline Females & 81 & 51.7 & 13.12 \\
\hline total & 151 & & \\
\hline $\begin{array}{c}\text { Patients with peripheral GGO and } \\
\text { consolidative pulmonary opacity at chest } \\
\text { CT }\end{array}$ & & & \\
\hline Males & 36 & 57.1 & 14.14 \\
\hline Females & 30 & 57.7 & 11.67 \\
\hline total & 66 & $53.4^{*}$ & 12.90 \\
\hline $\begin{array}{c}\text { Patients with slow-resolving RTI with } \\
\text { normal chest CT }\end{array}$ & & & \\
\hline Males & 31 & 49.2 & 15.87 \\
\hline Females & 38 & 48.7 & 13.28 \\
\hline total & 69 & $48.9^{*}$ & 14.35 \\
\hline
\end{tabular}

alterations of the bronchiolar structure to be commensurate with the patient's general clinical picture. Furthermore, three cases with lobar pneumonia and one case attributable to military tuberculosis were diagnosed. 66 patients had a CT pattern with peripheral ground-glass opacities (GGO) and nodular or mass-like GGO multifocal and or bilateral or monofocal features of lung involvement during severe acute respiratory syndrome coronavirus 2 (SARS-COV-2) according with the Expert Consensus Statement of the Radiological Society of North America reported in literature [13].

Laboratory characteristics of the study patients are reported in (Table 4). Patients with chest CT abnormalities (GGO and consolidative pulmonary opacities) had a lower WBC than patients with normal chest CT pattern, although not statistically significant. But if we consider the threshold of 4.0 thousand leukocytes per $\mu$, we find that $13 \%$ of patients with chest CT abnormalities were below this threshold. Other significantly different parameters between patients with chest $\mathrm{CT}$ abnormalities and normal chest CT were C-RP, ESR, and LDH. The quartet of the blood parameters WBC, LDH, ESR and $\mathrm{C}-\mathrm{RP}$ has a high positive predictive value (Table 5 ).

\section{Discussion}

The choice to perform a chest CT scan is since the chest X-ray appears to be a low sensitivity imaging investigation. An analysis of 1099 cases of COVID, only $14.7 \%$ of cases $(n=162)$ had changes on chest radiography while 840 patients $(76.4 \%)$ had changes on CT and GGO was the most common picture (65.5\%), followed by blurred thickening (48.7\%) and interstitial abnormalities (17\%) with bilateral involvement in about $50 \%$ of cases [14].

The patients with chest CT abnormalities (both multifocal and monofocal) were 66 (43.7\%) and they were all positive of COVID-19

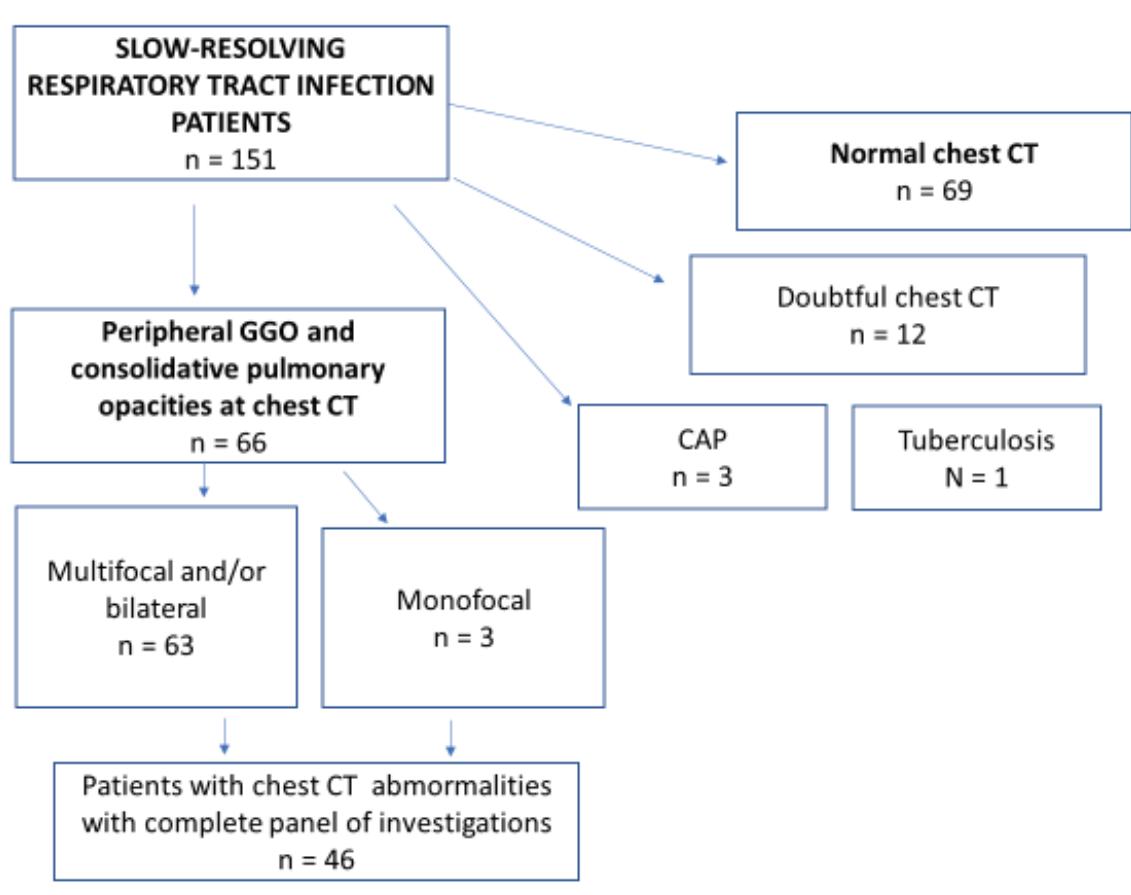

Figure 1: Study selection patients and characteristics. 
Citation: SESSA A, SCIENZA G, CLERICI G, LUMIA D (2020) Suspected cases of COVID-19 pneumonia in patients with slowresolving respiratory tract infections: the reverse path of primary care during first wave of Pandemia in Lombardy, Italy. Rea Int $\mathrm{J}$ of Community med and Pub Health.. Rea Int J of Community med and Pub Health. 1 (1): 042-046.

DOI: $10.37179 /$ rijcmph.00008.

Table 4: Panel of laboratory findings of the patients with chest CT abnormal pattern and with normal chest CT.

\begin{tabular}{|c|c|c|c|c|}
\hline $\begin{array}{l}\text { Laboratory } \\
\text { findings }\end{array}$ & $\begin{array}{l}\text { Patients with } \\
\text { chest CT with } \\
\text { GGO and } \\
\text { consolidative } \\
\text { pulmonary } \\
\text { opacities } n=46\end{array}$ & $\begin{array}{c}\text { Patients with } \\
\text { normal chest } \\
\text { CT } \\
n=38\end{array}$ & $\mathbf{t}$ & $P$ value \\
\hline $\begin{array}{c}\text { WBC } \times 1000 \times \mu l \\
(S D)\end{array}$ & $6.00(1.69)$ & $7.28(2.11)$ & 0.26 & 0.40 \\
\hline C-RP mg/dl (SD) & $32.3(51.8)$ & 4.62 (2.58) & 3.25 & $<0.001$ \\
\hline $\mathrm{ESR} \mathrm{mm} / \mathrm{h}$ (SD) & $29.8(23.3)$ & $13.9(15.4)$ & 3.61 & $<0.0005$ \\
\hline AST UI/l (SD) & $25.2(10.3)$ & $21.4(10.9)$ & 0.12 & 0.45 \\
\hline ALT UI/l (SD) & $28.8(16.5)$ & $27.4(37.7)$ & 0.01 & 0.49 \\
\hline LDH U/l (SD) & 221.2 (77.8) & 163.7 (26.76) & 4.28 & $<0.001$ \\
\hline $\begin{array}{l}\text { Range: } \\
\text { WBC 4.0-10.0 } \\
\text { C-RP < } 10 \\
\text { ESR }<25 \\
\text { AST }<34 \\
\text { ALT } 10-49 \\
\text { LDH } 120-246\end{array}$ & & & & \\
\hline
\end{tabular}

Table 5: Threshold level of laboratory tests of the patients with chest CT abnormal pattern and with normal chest CT.

\begin{tabular}{|c|c|c|c|c|c|}
\hline $\begin{array}{l}\text { Threshold of } \\
\text { laboratoOry } \\
\text { tests }\end{array}$ & $\begin{array}{l}\text { CT chest with } \\
\text { GGO and } \\
\text { consolidative } \\
\text { pulmonary } \\
\text { opacities } \\
\text { frequency } \\
\%(n / 46)\end{array}$ & $\begin{array}{c}\text { Normal CT } \\
\text { chest } \\
\text { frequency } \\
\%(n / 38)\end{array}$ & $\begin{array}{l}\text { Chi- } \\
\text { square } \\
\text { test }\end{array}$ & $\mathbf{p}$ & PPV \\
\hline $\begin{array}{l}\text { WBC }(<4.0 \\
{[\times 1000 / \mu l)}\end{array}$ & $13.0(6 / 46)$ & $0.0(0 / 38)$ & 5.46 & $<0.025$ & 1.00 \\
\hline C-RP (>10 mg/dl) & $47.8(22 / 46)$ & $2.6(1 / 38)$ & 22.95 & $<0.001$ & 0.743 \\
\hline $\mathrm{ESR}(>25 \mathrm{~mm} / \mathrm{h})$ & $56.5(26 / 46)$ & $18.4(7 / 38)$ & 12.66 & $<0.001$ & 0.956 \\
\hline AST (> 34 UI/l) & $15.2(7 / 46)$ & $5.2(2 / 38$ & 2.15 & 0.079 & n.c. \\
\hline $\operatorname{ALT}(>49 \mathrm{U} / \mathrm{l})$ & $13.0(6 / 46$ & $5.2(2 / 38)$ & 1.46 & 0.32 & n.c. \\
\hline LDH (>246 U/l) & $23.9(11 / 46)$ & $0.0(0 / 38)$ & 10.45 & $<0.01$ & 1.00 \\
\hline
\end{tabular}

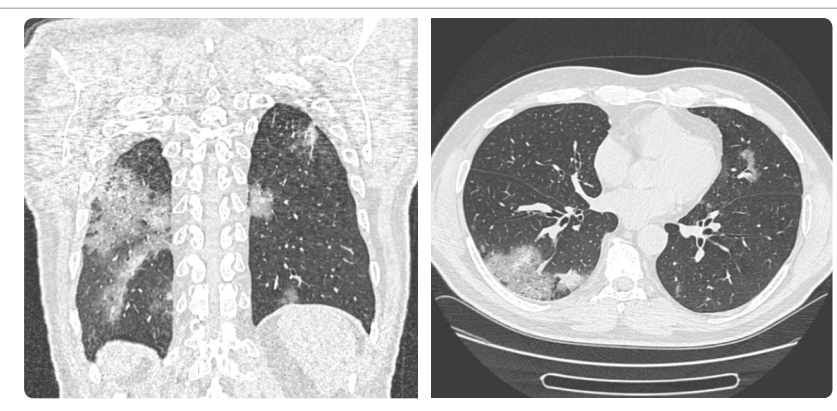

Figure 2: Picture of peripheral GGO and consolidative opacities in patients with slow-resolving RTI (\#51 patient, 48 ys male).

test of IgG, when tests were available for outpatients having the etiological confirmation of COVID-19 infection. (Figure 2). Patients with chest $\mathrm{CT}$ abnormalities were older than patients without chest
CT abnormalities according to five studies that pooled 468 patients with pneumonia where the mean age was 53 years [4]. Moreover, laboratory tests of our group of patients with COVID-19 pneumonia are like those reported in other studies [15-17] In the absence of a diagnostic test in patients with a slow-resolving RTI, at a time when coronavirus is circulating, the CT scan allows for an early diagnosis of COVID-19 pneumonia, a high-risk condition for hospitalization.

\section{Conclusions}

The path set up which involved highly sensitive imaging investigations and a panel of laboratory tests made it possible to identify an important number of pneumonias with characteristics of COVID-19 infection that otherwise would not have been diagnosed with the risk of a progression to respiratory failure which would inevitably lead to hospitalization. Patients were promptly treated at home with a protocol shared with the Infectious Diseases Department of the Varese Hospital and monitored by telephone for vital parameters and only three patients (4.5\%) have been hospitalized. Our study shows that when, or where, it is not possible to make a diagnostic test for COVID but in presence of respiratory symptoms evocative for lung involvement and with a set of investigations (chest CT and laboratory tests) it's possible to prevent hospitalization due to worsening of clinical conditions. Early identification of COVID-19 pneumonia in patients with slow-resolving RTI, their prompt treatment and their remote consultation and assessment can prevent severe complication as like as severe acute respiratory syndrome (SARS) responsible of hospitalization and intensive care unit admission. 63 out of 66 patients with COVID-19 pneumonia have been cared at their home.

\section{Acknowledgments}

A special thanks to Dr. Malek Isber of the Nuovo Centro Fisioterapico (Varese) for having promptly accepted and made available the diagnostic path of the patients. Thanks to Dr. Marcela Martini Pop for the collection and systematization of the data.

\section{Declaration of Conflicting Interests}

The authors declared non potential conflict of interest with respect to the research, authorship, and/or publication of this article.

\section{References}

1. Lu H, Stratton CW, Tang YW (2020) Outbreak of pneumonia of unknown etiology in Wuhan, China: the mystery and the miracle. J Med Virol 92: 401-402. Link: https://bit.ly/39sQgJW

2. Huang C, Wang Y, Li Z, Lili R, Zianping Z, et al. (2020) Clinical features of patients infected with 2019 novel coronavirus in Wuhan, China. Lancet 395: 497-506. Link: https://bit.ly/2BG34hx

3. www.who.int/emergencies/disease/novel-coronavirus-2019. Link: https://bit.ly/3qbm6AV

4. Lai CC, Yen HL, Cheng-YW, Ya-HW, Shun-CH, et al. (2020) Asymptomatic carrier state, acute respiratory disease and pneumonia due to severe acute respiratory syndrome coronavirus 2 (SARS-> CoV- 2: facts and myths. J Microbiol Immunol Infect. 53: 404-412. Link: https://bit. ly/2HSlz5J

5. Yang Y, Lu Q, Liu M, Yi-Xing W, An-Ran Z, et al. (2020) Epidemiological and clinical features of the 2019 novel coronavirus outbreak in China. medRxiv. Link: https://bit.ly/3liAK5T 
Citation: SESSA A, SCIENZA G, CLERICI G, LUMIA D (2020) Suspected cases of COVID-19 pneumonia in patients with slowresolving respiratory tract infections: the reverse path of primary care during first wave of Pandemia in Lombardy, Italy. Rea Int $\mathrm{J}$ of Community med and Pub Health.. Rea Int J of Community med and Pub Health. 1 (1): 042-046.

DOI: $10.37179 /$ rijcmph.00008.

6. Istituto Superiore di Sanità. ISS. Report of June 16, 2020 Task Force DMI COVID-19.

7. Li Q, Xuhua G, Peng W, Xiaoye W, Lei Z, et al. (2020) Early transmission dynamics in Whuan, China, of novel coronavirus infected pneumonia. NEJM. Link: https://bit.ly/3lujXwC

8. Backer JA, Don K, Jacco W (2020) ncubation period of 2019 novel coronavirus (2019-nCoV) infections among travelers from Wuhan, Chine, 20-28 January 2020. Euro Surveill 25: 2000062. Link: https:// bit.ly/2Vndb12

9. www.old.iss.it/site/RMI/influnet/pages/reportinflunet.aspx.

10. (2020) The Novel Coronavirus Pneumonia Emergency Response Epidemiology Team. The epidemiological characteristics of an outbreak of 2019 novel coronavirus disease (COVID-19) - China. China CDC Weekly. 2: 145-151. Link: https://bit.ly/36mkNXX

11. Chung M, Bernheim A, Mei X, Ning Z, Mingqian H, et al. (2020) CT imaging features of 2019 novel coronavirus (2019-nCov) Radiology 4: 200230. Link: https://bit.ly/3qhawEA

12. Rodriguez-Morales AJ, Cardona-Ospina JA, Gutierrez-Ocampo E, Rhuvi Villamizar-Peña, Yeimer Holguin-Rivera, et al. (2020) Clinical, laboratory and imaging features of COVID-19: A systematic review and meta- analysis. Travel Med Infect Dis 34: 101623. Link: https:// bit.ly/39CJ122

13. Simpson S, Kay FU, Abbara S, Sanjeev B, Jonathan HC, et al. (2020) Radiological Society of North America Expert Consensus Statement on reporting chest CT findings related to COVID-19. Endorsed by the Society of Thoracic Radiology, the American College of Radiology and RSNA. J Thorac Imaging 35: 219-227. Link: https://bit.ly/2HVRwKr

14. Guan WJ, Ni ZY, Hu Y, Wen-hua Liang, Chun-quan Ou, et al. (2020) Clinical characteristics of 2019 novel coronavirus infection in China. NEJM 382: 1708-1720. Link: https://bit.ly/2JmgAL6

15. Fan BE, Chong VC, Chan SS, Gek Hsiang Lim, Kian Guan Eric Lim, et al. (2020) Hematologic parameters in patients with COVID-19 infection. Am J Hematol 95: E131-E134. Link: https://bit.ly/3fRJ4s9

16. Lippi G, Plebani M (2020) Laboratory abnormalities in patients with COVID-19 infection. Clin Chem Lab Med 58: 1131-1134. Link: https:// bit.ly/2VWywiF

17. Ferrari D, Motta A, Strollo M, Giuseppe B, Massimo L (2020) Routine blood test sas a potential diagnostic tool for COVID-19. Clin Chem Lab Med 58: 1095-1099. Link: https://bit.ly/3qcbUIB 